\title{
Optimasi Metode Support Vector Machine dengan Discrete Wavelet Transform Untuk Pengenalan Karakter Plat Nomor Kendaraan
}

\author{
Edi Sugiarto', Fikri Budiman ${ }^{2}$ \\ ${ }^{1}$ Fakultas Ilmu Komputer Universias Dian Nuswantoro \\ Jl. Imam Bonjol No 207, (024) 3517261, e-mail: edi.sugiarto@dsn.dinus.ac.id \\ ${ }^{2}$ Fakultas IImu Komputer Universias Dian Nuswantoro \\ Jl. Imam Bonjol No 207, (024) 3517261, e-mail: fikri.budiman@dsn.dinus.ac.id
}

\section{ARTICLE INFO}

Article history:

Received 02 October 2020

Received in revised form 01 December 2020

Accepted 22 December 2020

Available online 31 January 2021

\begin{abstract}
Pengenalan karakter plat nomor kendaraan merupakan bagian dari Intelligent Transfport System yang memiliki peran penting untuk tujuan identifikasi plat nomor kendafraan secara resmi, penerapanya telah banyak dilakukan untuk identifikasi otomatis seperti pada tol elektronik, tempat parkir, $d s b$. Penelitian berkaitan dengan pengenalan karakter setidaknya memiliki fase-fase seperti segmentasi, fitur extraksi dan klasifikasi dimana tiap fase memiliki proses yang rumit. Keberhasilan dalam proses pengenalan karakter sangat tergantung dalam proses fitur ekstraksi, Sehingga pemilihan metode fitur ekstraksi yang dapat mengekstrak fitur-fitur yang relevan perlu dilakukan agar tingkat akurasi sistem pengenalan karakter dapat ditingkatkan. Discrete Wavelet Transform (DWT) telah banyak digunakan sebagai metode untuk ekstraksi fitur, metode ini melakukan ekstraksi dengan melakukan dekomposisi pada ruang vektor ke dalam ruang vektor bersarang dengan resolusi yang berbeda. Dalam penelitian ini metode discrete wavelet transform dikombinasikan dengan support vector machine untuk meningkatkan akurasi pengenalan karakter. Penelitian dilakukan dengan mengukur tingkat akurasi dari 100 citra plat nomor,selanjutnya dilakukan pengukuran tingkat akurasi dengan metode SVM Standar dan SVM yang telah dioptimasi dengan DWT, dengan penambahan metode discrete wavelet transform dan support vector machine tingkat akurasi klasifikasi mencapai 92\% dibandingkan dengan SVM Standar yang hanya mencapai $84 \%$, yang artinya dengan penambahan metode DWT dan SVM tingkat akurasi mendapatkan peningkatan sebesar $8 \%$.
\end{abstract}

Keywords: Support Vector Machine, Discrete Wavelet Transform, Pengenalan Karakter 


\section{Introduction}

Intelligent Transportation System (ITS) merupakan sistem yang bertujuan menyediakan layanan moda transportasi dan manajemen lalulintas yang dibagi menjadi dua bagian yaitu : Intelligent Infrastructure System dan Intelligent Vehicle System [1][2]. License Plate Recognition (LPR) merupakan sistem yang digunakan untuk mengidentifikasi kendaraan berdasarkan pengenalan plat nomor kendaraan [12], LPR ini memiliki peran yang penting karena plat nomor yang dimiliki pada setiap kendaraan digunakan sebagai identifikasi kendaraan secara resmi [3]. Penerapan teknologi Ini telah banyak dilakukan untuk identifikasi otomatis seperti pada tol elektronik, tempat parkir, serta akses daerah terlarang [12]. LPR atau pengenalan karakter plat nomor kendaraan dalam tahapan prosesnya memiliki tiga area penting yaitu: deteksi lokasi plat nomor, Segmentasi karakter Plat Nomor, dan Pengenalan Karakter Plat Nomor [2].

Penelitian berkaitan dengan pengenalan karakter setidaknya terdiri dari beberapa fase yaitu : segmentasi, fitur extraksi dan klasifikasi dimana tiap fase memiliki proses yang rumit[2]. Support vector machine (SVM) merupakan metode yang termasuk dalam supervised learning yang baik digunakan dalam persoalan klasifikasi, prediksi, maupun tergresi. Metode ini dapat digunakan untuk proses pengenalan karakter yakni pada tahap klasifikasi. Penggunaan metode SVM pernah dilakukan oleh edi sugiarto untuk pengenalan karakter[8], dalam penelitian tersebut metode SVM dioptimasi dengan algoritma genetika untuk mendapatkan parameter kernel yang terbaik pada tahap training. Hasil dari penelitian tersebut menunjukkan bahwa terdapat peningkatan akurasi ketika metode SVM dikombinasikan dengan algoritma genetika untuk mendapatkan paramater sigma dan pinalty yang tepat. Namun akurasi masih dapat ditingkatkan dengan mengoptimalkan proses pada ekstraksi fitur tiap karakter sebelum dilakukan proses klasifikasi [8].

Keberhasilan dalam proses pengenalan karakter sangat tergantung dalam proses fitur ekstraksi. Fitur ekstraksi merupakan proses pengambilan ciri (feature) dari suatu bentuk yang kemudian nilai yang didapatkan akan digunakan untuk analisis pada proses selanjutnya. Sehingga dalam hal ini diperlukan suatu teknik untuk memilih dan melakukan ekstraksi fitur yang relevan agar supaya performa dari sistem pengenalan karakter dapat ditingkatkan [3][4]

Wavelet transform merupakan metode transformasi yang mengadopsi metode Fourier Ttransform dan Short Time Fourier Transform (STFT). Metode wavelet ini bisa digunakan untuk fitur ekstraksi karena memiliki kemampuan untuk mendekomposisi ruang vektor ke dalam ruang vektor bersarang dengan resolusi yang berbeda. kemudian hasil dari dekomposisi tersebut dapat dilakukan analisa baik terhadap fungsi pada domain waktu maupun domain frekuensi [5]. Penerapan metode wavelet transform ini telah digunakan dalam berbagai bidang antaralain analisis signal, analisa numerik, pengolahan citra, komputer grafik, dll [5]. Adapun penerapan metode wavelet transform untuk ekstraksi fitur dalam berbagai penelitian yang telah dilakukan dijelaskan sebagai berikut: Edi Sugiarto [9] menggunakan metode discrete wavelet transform (DWT) untuk melakukan fitur ekstraksi pada citra huruf plat nomor kendaraan, DWT diterapkan dalam proses fitur ekstraksi huruf demi huruf untuk mendapatkan fitur-fitur terbaik, Nanik[5] menerapkan metode wavelet transform untuk melakukan ekstraksi fitur pada citra tekstur dalam sistem temu kembali. Geraldo [7] menerapkan wavelet transform untuk mengekstraksi fitur pada sistem klasifikasi dokumen.

Oleh karena itu tujuan penelitian ini adalah melakukan optimalisasi metode SVM dengan menambahkan metode Discrete Wavelete Transform untuk meningkatkan akurasi pengenalan karakter pada plat nomor kendaraan.

\section{Research Method}

\subsection{Penelitian Terkait}

Penelitian yang berkaitan dengan pengenalan karakter pernah dilakukan oleh Edi Sugiarto[8]. Dalam penelitian tersebut proses pengenalan dilakukan menggunakan metode Support Vector

TRANSFORMATIKA Vol. 18, No. 2, January 2021: 133-142 
Machine yang telah dioptimasi dengan Algoritma Genetika. Algoritma genetika diterapkan untuk melakukan parameter tunning pada SVM sehingga didapat nilai parameter sigma dan pinalti yang paling optimal. Proses pengenalan karakter dilakukan dalam dua tahap yaitu tahap pelatihan dan tahap pengenalan. dalam pengenalan karakter dilakukan dengan beberapa tahapan dimulai dari proses preprocessing dengan melakukan binerisasi citra, kemudian dilakukan segmentasi citra dengan menerapkan metode connected component labeling, kemudian dilakukan fitur ekstraksi menggunakan image matrix segmentation dengan membagi citra plat nomor menjadi matrik 5x5 sehingga didapatkan fitur terpilih. Selanjutnya tahap klasifikasi menggunakan metode Support Vector Machine yang lebih dahulu dilakukan parameter tunning menggunakan algoritma genetika sehingga didapat parameter terbaik dan kemudian klasifikasi dilakukan. Klasifikasi menggunakan metode SVM dengan kernel Radial Basis Function (RBF) dan pendekatan One Againts All (OAA). Pengujian akurasi dilakukan menggunakan confusion matrix. Pengukuranya dilakukan dengan 100 sampe citra plat nomor lalu diujikan, hasil pengukuran menunjukkan bahwa over all accurate untuk mengenali karakter secara sempurnya dengan metode tersebut hingga 91\%, dalam penelitian tersebut disimpulkan bahwa metode Support Vector Machine yang dioptimasi dengan algoritma genetika mampu meningkatkan akurasi pengenalan karakter. Namun akurasi tersebut dapat ditingkatkan dengan memperbaikai algoritma pada proses fitur ekstraksi [8].

Metode wavelet transform telah diterapkan oleh Rong[6] untuk mendeteksi plat nomor kendaraan. Penelitian dilakukan menggunakan dua tahapan yaitu tahap license plate training dan license plate recognition nomor. Langkah yang dilakukan dalam tahap training adalah dengan memasukkan citra input, kemudian dilakukan preprocessing dengan melakukan perubahan resolusi menjadi 32x64, dari resolusi tersebut selanjutnya fitur citra direduksi menjadi 7 kolom, proses training dilakukan menggunakan neural network. Kemudian pada tahap license plate recongition dilakukan preprocessing untuk citra input dengan mengubah resolusi menjadi yang sama yaitu 32x64 selanjutnya neural network digunakan untuk tahap pengenalan. dari hasil eksperimen yang telah dilakukan didapatkan tingkat akurasi pengenalan posisi plat nomor mencapai $94.7 \%$. hal yang membedakan dengan penelitian ini adalah bahwa penerapan metode wavelet transform pada penelitian tersebut digunakan untuk mencari fitur pada lokasi plat nomor. Sedangkan pada penelitian ini metode wavelet transform digunakan untuk mendapatkan fitur pada setiap karakter plat nomor kendaraan yang kemudian akan dikenali hurufnya.

\subsection{Discrete Wavelet Transform}

Wavelet transform merupakan metode yang mengadopsi metode Fourier Ttransform dan Short Time Fourier Transform (STFT). Transformasi fourier merupakan model transformasi yang memindahkan domain waktu kedalam domain frekuensi, dalam pemrosesan sinyal algoritma ini mampu menentukan frekuensi yang muncul, namun permasalahanya algoritma ini tidak dapat mengetahui secara pasti kapan frekuensi itu muncul. Berbeda dengan transformasi fourier, wavelet transform selain dapat memberikan informasi mengenai frekuensi yang muncul, juga dapat memberikan informasi skala dan durasi atau waktu [10]. Wavelet trasform melakukan dekomposisi pada ruang vektor kedalam sekumpulan ruang vektor bersarang dan dengan resolusi yang berbeda-beda, maka hasil dari dekomposisi tersebut dimungkinkan untuk dilakukan analisa baik terhadap fungsi pada domain waktu maupun domain frekuensi. Wavelet merepresentasikan suatu citra menggunakan transformasi diskrit 2D [5]. Proses transformasi menggunakan metode ini dilakukan dalam tahapan berikut ini : citra asli akan ditransformasikan menjadi 4 bagian sub image untuk mengganti citra aslinya, kemudian setiap sub image memiliki ukuran 1/4 dari citra aslinya. Lalu pada 3 sub image yang berada pada posisi kanan atas, kanan bawah, dan kiri bawah akan berisi frekuensi tinggi dari citra asli sehingga terlihat kasar. Sedangkan satu sub image pada bagian kiri atas akan terlihat halus karena pada sub image tersebut berisi frekuensi rendah. Dari 1

Optimasi Metode Support Vector Machine dengan Discrete Wavelet Transform Untuk Pengenalan Karakter Plat Nomor Kendaraan (Edi Sugiarto) 
sub image pada kiri atas tersebut kemudian ditransformasikan lagi menjadi menjadi 4 sub image baru, proses ini akan dilakukan terus menerus hingga level transformasi yang diinginkan [10].

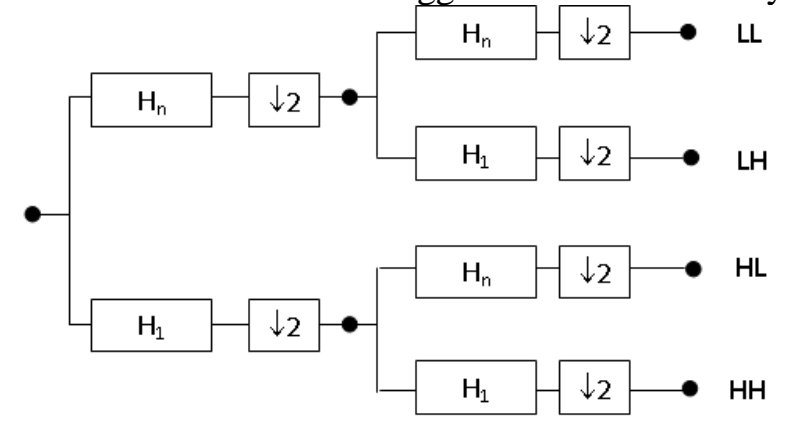

Gambar 1. Tahap transformasi pada wavelet 2D

Transformasi akan menghasilkan 4 sub image dengan 3 sub image berisi frekuensi tinggi (HL, $\mathrm{HH}, \mathrm{LH}$ ) dan satu sub image berisi frekuensi rendah (LL), hasil dari transformasi tersebut dapat dilihat pada gambar berikut:

\begin{tabular}{|c|c|}
\hline $\mathrm{LL}$ & $\mathrm{HL}$ \\
\hline $\mathrm{LH}$ & $\mathrm{HH}$ \\
\hline Aproximation & Vertical Details \\
\hline Horizontal Details & Diagonal Details \\
\hline
\end{tabular}$=$\begin{tabular}{|c|c|}
\hline $\mathrm{C}_{\mathrm{A}}$ & $\mathrm{C}_{\mathrm{V}}$ \\
\hline $\mathrm{C}_{\mathrm{H}}$ & $\mathrm{C}_{\mathrm{D}}$ \\
\hline
\end{tabular}

Gambar 2 . Hasil transformasi

\subsection{Support Vector Machine}

Support Vector Machine atau SVM telah diperkenalkan vladimir vanpik pada tahun 1992 sebagai metode machine learning dengan rangkaian harmonisasi dan konsep-konsep unggulan dalam bidang pengenalan pola[11]. SVM merupakan metode yang termasuk dalam suppervised learning dan sangat baikdigunakan dalam persoalan prediksi, klasifikasi, maupun regresi. SVM bekerja dalam konsep dasar yakni menemukan hyperplane terbaik yang digunakan sebagai kunci pemisah antara 2 kelas pada input space.

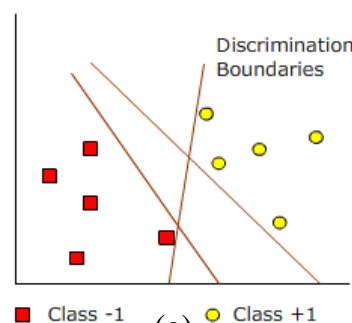

(a)

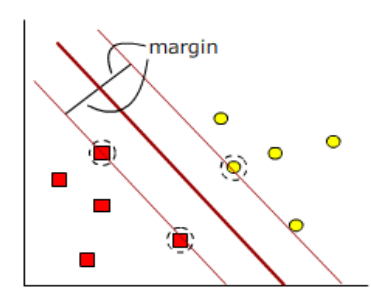

(b)

Gambar 3. SVM mencari hyperplane terbaik untuk memisahkan dua kelas

Hyperplane yang terbaik diperoleh dengan melakukan pengukuran pada margin hyperplane kemudian mencari titik maksimalnya. Margin merupakan jarak antara hyperplane dengan pola terdekat dari masing-masing kelas. Pola terdekat tersebut disebut Support Vector. Fungsi tersebut didefinisikan sbb: 


$$
\begin{aligned}
& \mathrm{g}(\mathrm{x}):=\operatorname{sqn}(\mathrm{f}(\mathrm{x})) \\
& \text { dengan } \\
& f(x)=W^{\top} X+b
\end{aligned}
$$

kemudian jarak antara kedua hyperplane dari kedua kelas tersebut akan dihitung untuk mendapatkan margin. Secara spesifik margin dihitung berdasarkan rumus berikut :

$$
\begin{aligned}
\left(W X_{1}+b=+1\right)-\left(W X_{2}+b=-1\right) & =W\left(X_{1}-X_{2}\right)=2=> \\
\left(\frac{w}{\|w\|}(x 1-x 2)\right) & =\frac{2}{\|w\|}
\end{aligned}
$$

SVM dalam menemukan fungsi pemisah dengan margin yang maksimal dapat dijelaskan pada gambar berikut:

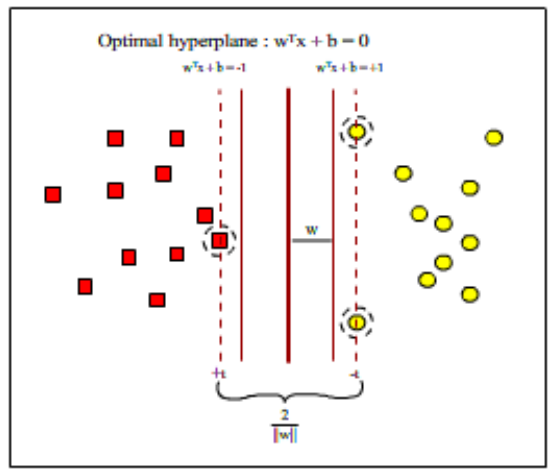

Gambar 4 . SVM mencari fungsi pemisah yang optimal

\subsection{Pengenalan Karakter}

Proses pengenalan karakter ini dilakukan dalam dua tahapan yaitu tahap training atau pelatihan dan tahap recognition atau pengenalan. Tahap training dilakukan untuk memberikan data awal dan dataset yang akan digunakan sebagai basis pengetahuan dalam proses pengenalan. sedangkan pada tahap recognition dilakukan untuk melakukan proses klasifikasi dari fitur yang diperoleh untuk mencari kelas yang terbaik sebagai hasil dari pengenalan karakter, maka rangkaian proses tersebut digambarkan dalam diagram berikut: 


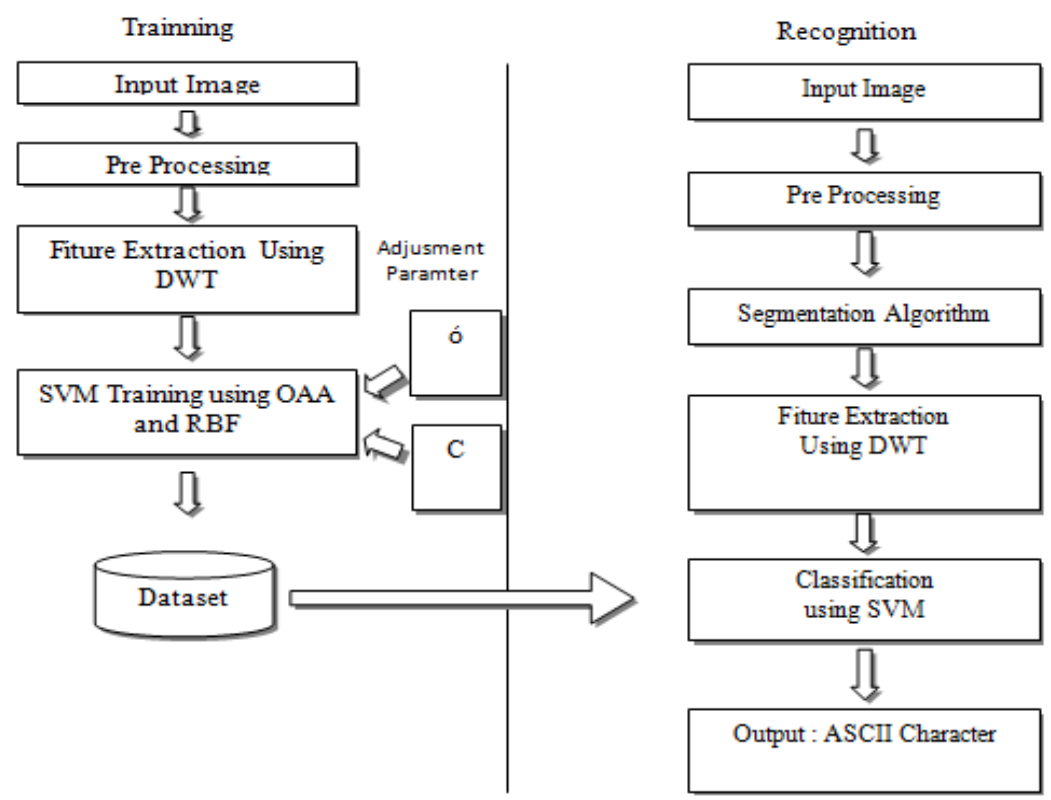

Gambar 5. Tahapan pengenalan karakter

\subsubsection{Proses Training}

Proses training atau pelatihan dilakukan dimulai dari citra input, segmentasi, fitur ekstraksi dengan DWT dan proses training untuk pembentukan dataset.

\section{- Input Image dalam proses training}

Gambar atau citra yang digunakan pada tahap ini adalah gambar plat nomor yang berupa citra karakter alphanumeric yang menggambarkan citra angka dan huruf yang digunakan dalam plat nomor yaitu : A-Z, 0-9.

\section{- Preprocessing}

Tahap ini digunakan untuk menentukan kualitas citra yang akan diekstraksi. Langkah yang dilakukan pertama adalah mengubah citra dari RGB kedalam citra biner (binerisasi).
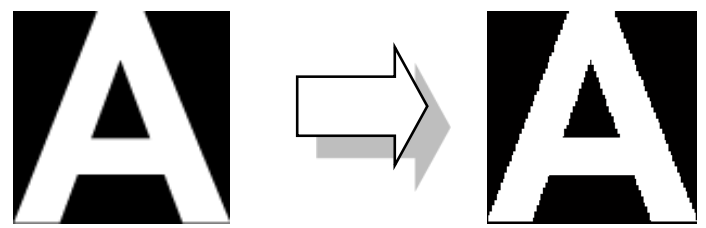

Gambar 6. Proses binerisasi citra

- Fiture extraction

Citra hasil setelah preprocessing selanjutnya akan diambil fiturnya pada tahap ini. Pada tahap ini Discrete Wavelet Transform digunakan untuk mendapatkan fitur dengan cara mengurangi dimensi gambar dari dimensi tinggi ke dimensi rendah. Sehingga pada tahap ini akan diperoleh empat sub citra yaitu : Aproximasi (cA), frekuensi tinggi horisontal $(\mathrm{cH})$, frekuensi tinggi vertikal $(\mathrm{cV})$, dan frekuensi tinggi diagonal $(\mathrm{cD})$.

TRANSFORMATIKA Vol. 18, No. 2, January 2021 : $133-142$ 


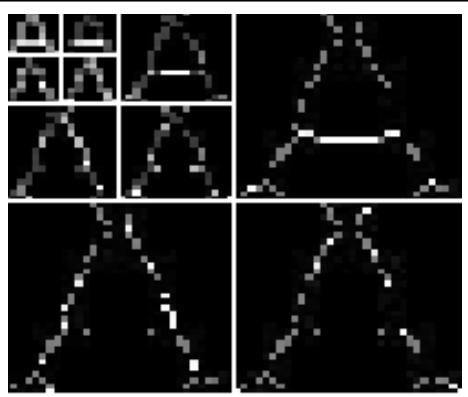

Gambar 7. Skema dekomposisi wavelet 3 level

\section{- Training}

Setelah ekstraksi fitur selesai, maka didapat nilai energi dan standar deviasi yang digunakan sebagai fitur pada setiap citra. Hasil ekstraksi fitur ini kemudian digunakan pada tahap pelatihan/training untuk parameter SVM yaitu Number of Support Vector (NSV), Error Rate, Weigh (w), Bias (b). Sedangkan paramter sigma (ó) dan pinalti (c) didapat berdasarkan data training yang digunakan.

\subsubsection{Proses Recognition}

Proses pengenalan karakter merupakan tahapan berikutnya setelah tahap training/pelatihan, tahap ini dilakukan untuk mendapatkan pola-pola karakter yang sesuai. Adapun tahapan pada proses ini antaralain :preprocessing, segmentation, fiture extraction, dan classification.

\section{- Preprocessing}

Tahap preprocessing pada proses pengenalan dilakukan untuk menentukan kulalitas citra sebelum diekstraksi, citra input pada tahap ini berupa citra plat nomor yang telah diambil bagian yang diperlukan yaitu satu kerangka plat lengkap dengan nomor kendaraan. Prosesproses yang dilakukan pada tahap ini yaitu: binerisasi citra, memilih area yang diinginkan atau region of interest (ROI), dan memperbaiki kualitas citra (image enhancement).

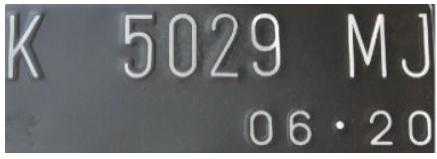

(A)

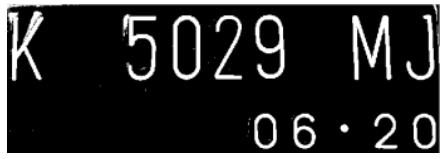

(B)

Gambar 8. Binerisasi citra, (A) Data input berupa citra RGB (B) citra setelah binerisasi

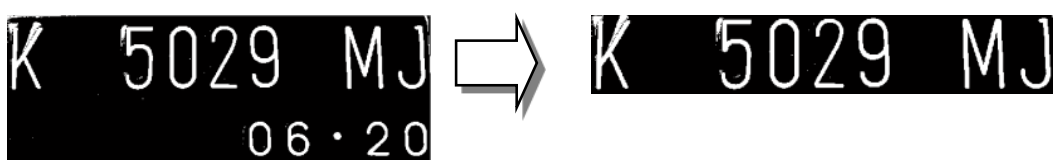

Gambar 9. Menentukan area yang diperlukan

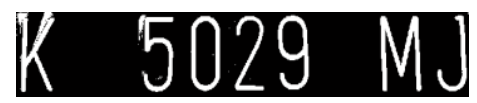

(A)

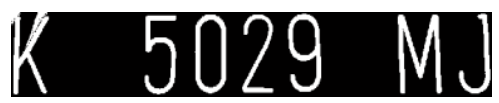

(B)

Gambar 10. (A) Citra input dengan noise

(B) Citra hasil image enchancement

\section{- Segmentation}


Setelah tahap preprocessing dilakukan maka akan didapat citra plat nomor yang sesuai, langkah selanjutnya melakukan segmentasi citra plat nomor agar nilai angka atau huruf pada citra plat dapat dipisah agar dapat diekstaksi fiturnya huruf demi huruf. Pada tahap ini digunakan metode connected component labeling.

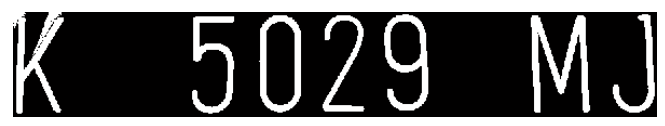

(A)

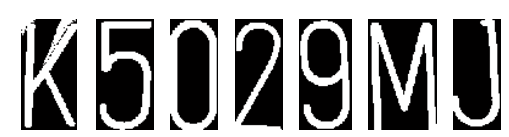

(B)

Gambar 11. (A) Citra input (B) Citra hasil segmentasi

\section{- Fiture Extraction}

Pada tahap ini fitur-fitur pada tiap gambar yang telah disegmentasi akan dicari, sehingga ketika hasil segmentasi sebanyak 7 citra maka setelah tahap ini akan menghasilkan 7 fitur yang merupakan fitur-fitur dari setiap citra huruf tersebut. Pada tahap ini ekstraksi fitur menggunakan metode Discrete Wavelete Transform.

\section{- Classification}

Tahap terakhir pada pengenalan karakter ini adalah tahap klasifikasi, pada tahap ini klasifikasi dilakukan berdasarkan fitur-fitur pada citra yang telah diekstraksi. Fitur-fitur hasil ekstraksi tersebut kemudian diklasifikasi menggunakan fungsi SVM yang terdapat pada STPRTOOl. STPRTOOL merupakan suatu perangkat untuk pengenalan pola yang didalamnya berisi kumpulan fungsi-fungsi dan terintegrasi dengan matlab, salah satunya adalah fungsi SVMClASS. Langkah yang dilakukan pada tahap ini yaitu:

1. Mengambil dataset yang telah dibuat saat training.

2. Menentukan model data dengan fungsi oaasvm untuk pendekatan one againts all.

3. Terakhir yaitu dengan menggunakan SVM untuk klasifikasi, fungsi SVM menggunakan fungsi SVMCLASS yang terdapat pada library STPRTOOL.

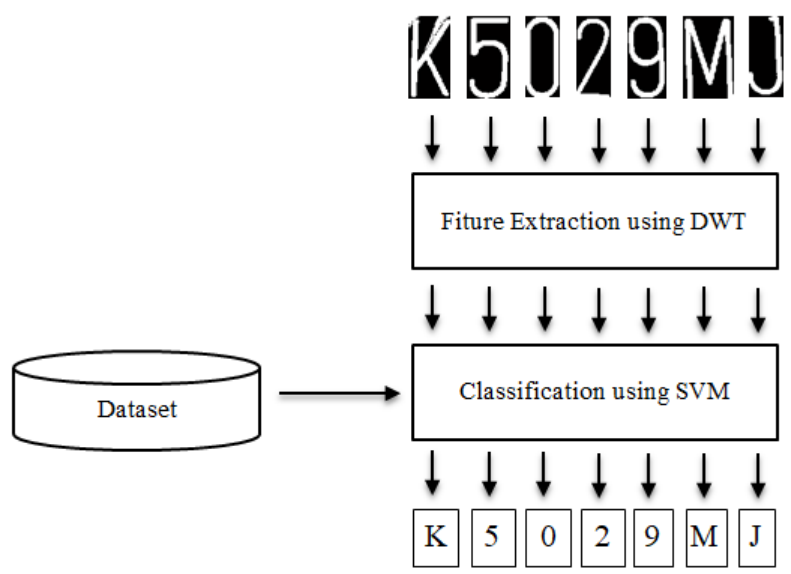

Gambar 12. Proses klasifikasi

\section{Results and Analysis}

Pengujian dilakukan menggunakan 100 citra sample dalam berbagai kondisi. Eksperimen dilakukan dengan membandingkan hasil dari proses pengenalan menggunakan metode SVM 
standar dengan SVM yang telah dioptimasi menggunakan metode Discrete Wavelet Transform. Eksperimen dilakukan pertama kali dengan melakukan ekstraksi fitur dengan metode DWT. Kemudian dilakukan proses training untuk membentuk model menggunakan SVM dengan nilai parameter deviasi (ó) adalah 0.726 dan pinalti (C) adalah 14.365 dengan error rate pada proses pelatihan sebesar 0.0236. setelah proses training selesai dan telah diketahui parameter SVM yang terbaik langkah selanjutnya adalah proses recognition (pengenalan) dengan melakukan simulasi pengenalan pada tiap-tiap citra plat nomor untuk diujikan. Akurasi selanjutnya diukur menggunakan confusion matrix dan hasil pengukuran dapat dilihat pada tabel berikut:

Tabel 1. Tabel pengukuran tingkat akurasi

\begin{tabular}{|l|c|c|c|c|c|}
\hline Metode & $\begin{array}{c}\text { True } \\
\text { Positive } \\
\text { (TP) }\end{array}$ & $\begin{array}{c}\text { False } \\
\text { Positive } \\
\text { (FP) }\end{array}$ & $\begin{array}{c}\text { True } \\
\text { Negative } \\
\text { (TN) }\end{array}$ & $\begin{array}{c}\text { False } \\
\text { Negative } \\
\text { (FN) }\end{array}$ & $\begin{array}{c}\text { Over All } \\
\text { Accuracy } \\
\text { (AC) }\end{array}$ \\
\hline SVM & 77 & 16 & 7 & 0 & 0,84 \\
\hline DWT-SVM & 85 & 8 & 7 & 0 & 0.92 \\
\hline
\end{tabular}

Dari hasil pengukuran menggunakan confusion matrix dapat diketahui bahwa dengan penambahan Discrete Wavelet Transform pada proses fitur ekstraksi dapat meningkatkan akurasi klasifikasi metode SVM, dalam penelitian ini peningkatan akurasi DWT-SVM dibandingkan dengan SVM yang standar hingga 8\% dimana over all accuracy untuk SVM standar sebesar 84\% dibanding dengan DWT-SVM yang memiliki over all accuracy hingga 92\%.

\section{Conclusion}

Dari eksperimen yang telah dilakukan dengan penerapan DWT pada tahap fitur ekstraksi dan SVM pada tahap klasifikasi, dapat disimpulkan bahwa hasil eksperimen mampu meningkatkan akurasi pengenalan karakter plat nomor hingga 8\% dibandingkan dengan metode SVM standar, hal ini membuktikan metode DWT dapat melakukan ekstraksi ciri dengan baik. Dalam percobaan yang telah dilakukan dan dengan penambahan algoritma DWT pada tahap fitur ekstraksi dapat meningkatkan akurasi hingga sebesar 92\% dari 100 sample citra plat nomor kendaraan yang diujikan.

\section{References}

[1]. W. Wen, X. Huang, L. Yang, Z. Yang and P. Zhang, "Vehicle License Plate Location Method Based-on Wavelet Transform," 2009 International Joint Conference on Computational Sciences and Optimization, Sanya, Hainan, 2009, pp. 381-384, doi: 10.1109/CSO.2009.219.

[2]. Sugiarto, Edi. "Pengenalan Karakter Pada Plat Nomor Kendaraan Berbasis Support Vector Machine". Techno. Com, 2013 : 12(1), 1-15.

[3]. Swati Jagtap, "Analysis of Feature Extraction Techniques for Vehicle Number Plate Detection", International Journal of Computer Science and Information Technologies, 2015 : Vol. 6 (6), 5342-5346.

[4]. Y. Qiu, M. Sun and W. Zhou, "License Plate Extraction Based on Vertical Edge Detection and Mathematical Morphology," 2009 International Conference on Computational Intelligence and Software Engineering, Wuhan, 2009, pp. 1-5, doi: 10.1109/CISE.2009.5364222.

[5]. Nanik Suciati, "Ekstraksi Fitur Berbasis Wavelet Pada Sistem Temu Kembali Citra Tekstur", jurnal SCAN, 2013 : Vol. VII No 2, ISSN: 1978-0087. 
[6]. R. T. Lee and K. Hung, "Real-Time Vehicle License Plate Recognition Based on 1-D Discrete Periodic Wavelet Transform," 2012 International Symposium on Computer, Consumer and Control, Taichung, 2012, pp. 914-917, doi: 10.1109/IS3C.2012.233.

[7]. G. Xexéo, J. d. Souza, P. F. Castro and W. A. Pinheiro, "Using Wavelets to Classify Documents," 2008 IEEE/WIC/ACM International Conference on Web Intelligence and Intelligent Agent Technology, Sydney, NSW, 2008, pp. 272-278, doi: 10.1109/WIIAT.2008.221.

[8]. Edi Sugiarto, Cahaya Jatmoko, "Pengenalan Karakter Pada Plat Nomor Kendaraan Berbasis Support Vector Machine dan Genetic Algorithm", Science and Engineering National Seminar 2 (SENS2), 2019, pp. 17-24, ISBN:978-602-0960-43-3.

[9]. Edi sugiarto, "Fitur Ekstraksi Berbasis Discrete Wavelet Transform Untuk Pengenalan Karakter Pada Plat Nomor Kendaraan", Techno.COM Vol. 16 No 3, 2017 : 292-299.

[10]. Darma Putra, "Pengolahan Citra Digital", Yogyakarta : Penerbit Andi, 2010.

[11]. Budi Santosa,"Datamining Teknik Pemanfaatan Data untuk Keperluan Bisnis, Teori dan Aplikasi", Yogyakarta : Graha Ilmu, 2007.

[12]. Zheng L., He X. "Character Segmentation for License Plate Recognition by K-Means Algorithm". Image Analysis and Processing - ICIAP, 2011. Lecture Notes in Computer Science, vol 6979. Springer, Berlin, Heidelberg. 